\title{
MEDIATORS IN ANAPHYLAXIS OF GUINEA-PIG SMALL INTESTINE
}

\author{
Norio KURIHARA and Katsuhiro SHIBATA \\ Department of Pharmacology, School of Medicine, \\ Gunma University, Maebashi, Japan
}

Received for publication December 7, 1971

With the use of a nonsensitized segment serving as indicator, the release of histamine or other substances during anaphylactic contraction in the isolated sensitized guinea-pig ileum was demonstrated (1). Histamine releasc in anaphylaxis was mcasured by immersing sensitized guinea-pig tissues including the small intestine in Tyrode solution containing the antigen (2,3). Attempts to demonstrate directly the release of 5-hydroxytryptamine (5HT) from the sensitized guinea-pig ileum have been unsuccessful $(4,5)$. In most of these studies histamine and 5-HT were assayed biologically. Biological assay requires great skill in techniques. The purpose of the present experiment is to determine spectrophotofluorometrically the possible release of histamine and 5-HT from the sensitized isolated guinea-pig small intestine by antigen, as first studies regarding the effect of various drugs on the release of mediators.

\section{MATERIALS AND METHODS}

A total of 30 male guinea-pigs weighing 400 to $600 \mathrm{~g}$ (at the time of sacrifice) were used. These had been exposed to laboratory conditions for at least 5 weeks prior to sacrifice. The animals were fed on a commercial solid diet (Oriental, Co., Japan) and water was allowed ad libitum.

In experiment I, the animals were divided into 4 groups: $a$ ) actively sensitized animals, b) nonsensitized animals, control for group $a, c$ ) nonsensitized animals, where the small intestines were to be passively sensitized with serum of immunized rabbit and $d$ ) nonsensitized animals, control for group $c$, where the small intestines were to be incubated with serum of nonimmunized rabbit. Experiment II, included 2 groups ( $e$ and $f$ ) of nonsensitized animals, where the small intestines were to be passively sensitized with serum of immunized rabbit. There were five in each group.

\section{Active sensitization}

Thirty days after a subcutaneous injection of $5 \mathrm{mg}$ of crystalline ovalbumin (Sigma Chemical Co., U.S.A.) together with $0.5 \mathrm{mg}$ of Fround's complete adjuvant (Difco Laboratories, U.S.A.), guinea-pigs were given a single subcutaneous booster shot with $20 \mathrm{mg}$ of the same antigen without the adjuvant. Five days after the last injection they were fasted overnight, sacrificed by a blow on the head and exsanguinated by decapitation. The total 
small intestines were excised by cutting both ends and were used for the anaphylaxis test without cutting into segments.

Passive sensitization

Thirty days after a subcutancous injection of $10 \mathrm{mg}$ of the same antigen together with $1.0 \mathrm{ml}$ of the same adjuvant, an albino rabbit was given four injections of $20 \mathrm{mg}$ of the antigen as booster. The serum was obtained 5 days after the last injection, lyophilized and stored in a deep freezer, then used for the passive test in dilution of $1: 200$ with Tyrode solution. Similarly as in active sensitization, total non-segmented small intestines were incubated at $37 \mathrm{C}$ in $100 \mathrm{ml}$ of Tyrode solution containing rabbit serum and shook at a low speed for one hour.

\section{Precipitin test}

The lest was carried out 1 day prior to sacrificing the immunized animals. The precipitin titers were $1: 64$ or $1: 128$ in guinca-pigs and $1: 128$ in rabbits.

in vitro anaphylaxis

The small intestines of actively sensitized guinea-pigs were incubated in $20 \mathrm{ml}$ Tyrode solution at $37 \mathrm{C}$ and stired by bubbling oxygen. And $2.5 \times 10^{-5} \mathrm{~g} / \mathrm{ml}$ of the antigen was added and the whole was shaken at a low speed for $5 \mathrm{~min}$. Tyrode solution was then filtered and divided into 2 ampules. Immediately after, each was lyophilized and stored in a deep freezer until the assay of histamine and 5-HT, respectively.

Passively sensitized small intestines were also incubated in $20 \mathrm{ml}$ Tyrode solution at $37 \mathrm{C}$, well stirred by bubbling oxygen, and the antigen added in amount of $2.5 \times 10^{-5} \mathrm{~g} / \mathrm{ml}$ (in groups of experiment I), $10^{-4} \mathrm{~g} / \mathrm{ml}$ (in group $e$ of experiment II) and $10^{-3} \mathrm{~g} / \mathrm{ml}$ (in group $f$ of experiment II). Tyrode solution was then similarly treated as described above for active sensitization.

\section{Chemical assay}

Histamine (histamine dihydrochloride, Merck AG., Germany) and 5-HT (5-hydroxytryptamine creatinine sulfate complex, Sigma Chemical Co., U.S.A.) were determined spectrophotofluorometrically by the methods of Shore et al. (6) and of modification by Saikawa (7) of Weissbach ct al. (8), respectively.

Histamine and 5-HT were calculated as the free base and the values were expressed in $\mu \mathrm{g}$ per $\mathrm{g}$ of dry tissue weight.

\section{RESULTS}

Experiment I. Rekease of mediators from actirely and passively sensitized guinea-pig small intestines

Table 1 summerizes the results of histamine determination in Tyrode solution released from the small intestines of guinea-pigs in 4 groups during anaphylaxis. The values of groups $a$ and $c$ were $0.31-0.04$ and $0.32 \doteq 0.02 \mu \mathrm{g} / \mathrm{g}$, respectively. In groups $b$ and $a$ histamine was undetectable. In all the 4 groups 5-HT was undetectable owing to disturbance of interfering substance and/or low sensitivity of the method.

Experiment II. Relationship between the release of mediators from passively sensitized guinea- 
TABLE 1. Histamine released by antigen from guinea-pig small intestine.

\begin{tabular}{|c|c|c|c|}
\hline Groups & Treatment & $\begin{array}{l}\text { No. of } \\
\text { animals }\end{array}$ & $\begin{array}{c}\text { Histamine release }(\mu \mathrm{g} / \mathrm{g}) \\
\quad \text { Mean } \pm \text { S.E. }\end{array}$ \\
\hline $\mathbf{a}$ & Active sensitization & 5 & $0.31 \pm 0.04$ \\
\hline b & Controls* & 5 & Not detectable \\
\hline c & Passive sensitization & 5 & $0.32+0.02$ \\
\hline$d$ & Controls** & 5 & Not detectable \\
\hline
\end{tabular}

* Small intestine of intact animals.

** Small intestine incubated with serum of intact rabbit.

The antigen was added in concentration of $2.5 \times 10^{-3} \mathrm{~g} / \mathrm{ml}$.

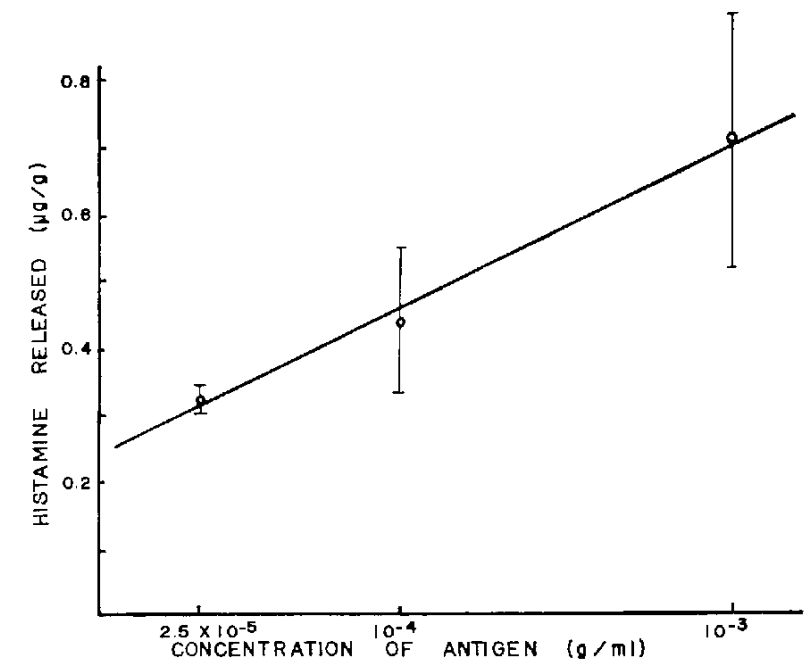

FIG. 1. Effect of antigen on histamine release from passively sensitized guinea-pig intestine. Vertical line indicates the S.E. of the mean. The values increased with elevation in the concentration of antigen.

pig small intestines and the concentrafion of antigen

Fig. 1. shows the results of histamine determination released from the small intestines of guinea-pigs during anaphylaxis in group $c$ of experiment $\mathbf{I}$ and groups $e$ and $f$ of experiment II. Histamine release and variation increased along with the increase in concentration of the antigen. In all groups of experiment II, 5-HT was undetectable as it was in experiment $\mathbf{I}$.

\section{DISCUSSION}

Yamasaki (9), who used the method of suspending a sensitized segment of guinea-pig ileum in a bath logether with a normal nonsensitized segment, reported the results of his experiments as follows: the mediator released in anaphylaxis from the isolated segment of guinea-pig ileum was histamine itself, because the contraction of the normal nonsensitized segment was completcly inhibited by the pretreatment with pyrilamine. Histamine was 
not however totally responsible for the anaphylactic contraction, as the contraction of the sensitized segment was inhibited only partly by the pretreatment with the same drug.

Mongar and Schild (2) and Kamimura (3) biologically measured the amount of histamine released in Tyrode solution containing the antigen after immersing thin pieces of 13 tissues including the small intestine taken from actively sensitized guinea-pigs. In these studies thin pieces of longitudinally incised intestines weighing $100-200 \mathrm{mg}$ were used. In the present experiment the total small intestine weighing about $12 \mathrm{~g}$ in wet weight was used without segmentation. Therefore the ratio of spontaneous release of histamine from damaged cells of the small intestine suspended in Tyrode solution to the release of histamine by antigen add may be less. This is concluded from the fact that histamine release from the small intestine was undetectable in the control groups.

As experimental conditions in the above described studies differ in many points, a comparison of the results of these studies with those of the present experiment is not feasible.

In the present experiment, the amount of histamine release was fluorometrically measured in antigen-add Tyrode solution by immersing actively and passively sensitized small intestines of guinea-pigs. For the purpose of less variation in values, it was expressed in $\mu g$ per $g$ of dry tissue weight. When the antigen was added in concentration of $2.5 \times 10^{-5}$ $\mathrm{g} / \mathrm{ml}$ the values were approx. $0.3 \mu \mathrm{g} / \mathrm{g}$ in both active and passive sensitizations. In the passive test the values and variations increased along with the increase in the concentration of the antigen. The values showed the least variation, when the antigen was added in concentration of $2.5 \times 10^{-5} \mathrm{~g} / \mathrm{ml}$, therefore this amount was hereafter used in experiments.

The procedures by spectrofluorometrical assay being simple as compared with those by biological assay, the methods used in the present experiment are applicable to the determination of histamine released in anaphylaxis of guinea-pig tissues.

\section{SUMMARY}

Histamine and 5-HT release in anaphylaxis were measured spectrophotofluorometrically by immersing actively and passively sensitized guinea-pig small intestines in Tyrode solution containing crystalline ovalbumin.

Histamine relcase from actively and passively sensitized small intestines by the antigen $\left(2.5 \times 10^{-5} \mathrm{~g} / \mathrm{ml}\right)$ was approx. $0.3 \mu \mathrm{g} / \mathrm{g}$ in both cases. Histamine release from passively sensitized small intestines in anaphylaxis and variation increased along with the inrease in concentration of the antigen.

5-HT release was undetectable in all cases owing to the disturbance of interfering substance and/or low sensitivity of the method.

\section{REFERENCES}

1) Dwortizky, M.: Am. J. Physiol. 197, 31 (1959)

2) Mongar, J.L. And Schild, H.O.: J. Physiol. 118, 461 (1952)

3) Kamimura, Y.: Folia pharmac. jap. 53, 680 (1957)

4) Fink, M.A. And Gardner, C.E.: Proc. Soc. exp. Biol. Med. 97, 554 (1958)

5) Borḱus, L.O. AND Westerholm, B.: Acta physiol. scand. 56, 17 (1962) 
6) Shore, P.A., Burkhulter, A. And Cohn, V.H., Ir.: J. Pharmac, exp. Ther, 127, 182 (1959)

7) SAIKAWA, H.: Jap. J. Allerg. 14, 312 (1965)

8) Weissbach, H., Waalkes, T.P. and Udenfriend, S.: J. biol. Chem. 230, 865 (1958)

9) YAmasaki, H.: Jap. J. Allerg. 10, 19 (1961) 